\title{
ADDENDA ET ERRATA
}

Page 6, à la liste des membres «admis comme membres honoraires s ajoutez Baltié.

- 34, ligne 5 (en remontant), au lieu de aphothécies, lise $z$ apothécies.

- 85, ligne 14 (en remontant, dans la colonne de gauche), au lieu de Reb, lisez Rab.

- 86, ligne 15 (en remontant, dans la colonne de gauche), au lieu de Reb, lisez Rab.

- 120, ligne 2 de l'explication des figures, au lieu de foliole, lisez fiole.

- 123, ligne 15, au lieu de ci-après, lisez ci-dessus.

- 147, ligne 4, au lieu de développée, lisez desséchée.

- 160, ligne 6, au lieu de ștriata, lisez stricta.

- 160, ligne 13, au lieu de Rout, lisez Reut.

- 184, ligne 5 , au lieu de jadis, lisez jamais.

- 202, ligne 9 (en remontant), au lieu de $1 \mathrm{~mm}$. alta, lisez $1 \mathrm{~m}$. alta.

- 325, ligne 9, au lieu de Schatglacer Schichtea, lisez Schatzlarer Schichten.

- 338, ligne 10 (en remontant), au lieu de des plantes, lisez des graines des plantes.

- 353, ligne 18, au lieu de 14 juin, lisez 7 juin.

Dans les articles de MM. Finet et Gagnepain :

Page 522, ligne 4 (en remontant), au lieu de feuilles entières, lisez feuilles simples.

- 522, ligne 16 (en remontant), ajoutez : Akènes avec parfois une houppe de poils (C. fasciculiflora).

- 523, ligne 24: au lieu de $\mathrm{n}^{\circ} 177$, lisez $\mathrm{n}^{\circ} 477$.

- 524, après la ligne 12, ajoutez :

Obs. - Akènes glabres ou à peine velus au sommet; dans la fleur, trois fois plus courts que la queue plumeuse. Filets des étamines glabres, linéaires, un peu plus larges à la base. Anthères elliptiques; loges glabres, contiguës, à déhiscence latérale. Sépales 6-7, glabres, elliptiques ou un peu acuminés. Fleurs paraissant avant les feuilles.

- 540, après la ligne 28 , ajoutez :

Obs. - Akènes ovoides, velus; dans la fleur, 4-5 fois plus courts que la queue plumeuse, plus tard jusqu'à quinze fois plus courts. Étamines plus courtes que les sépales: filets linéaires, dilatés au milieu. velus; anthères elliptiques-rectangulaires, glabres; loges contiguës. Sépales 4, lancéolés, à trois nervures principales, velus sur les bords. - La var. latisecta se distingue simplement par les segments plus larges de ses folioles.

- 547, ligne 5 (en remontant), au lieu de il se distingue, lisez elle se distingue.

- 602, après la ligne 12, ajoutez : 
Obs. - Akènes fusiformes courts, velus, à style presque nul dans la fleur. Étamines glabres, beaucoup plus courtes que les sépales; filet nul; connectif épaissi surmontant les loges. Staminodes filiformes à peine insensiblement renflés vers le haut. Sépales 2-3 fois plus longs que les étamines, concaves, velus extérieurement.

Page 608, après la dernière ligne, ajoutez:

Obs, - Sépales elliptiques, rarement acuminés. Étamines à filet filiforme régulier. Anthère lancéolée mucronée. Akìne étalé, pédiculé, à stigmate subsessile; pédicule égal à l'ovaire.

- 609, après la ligne 4, ajoutez :

Obs. - Sépales... Étamines à filet filiforme un peu dilaté au sommet; anthère elliptique, mucronulée. Akène étalé, pédiculé; pédicule égal à l'ovaire; stigmate non sessile, droit ou circiné égal au pédicule.

- 611, ligne 2i : au lieu de cinquième de égal l'akène mùr, lisez cinquième de l'akène mûr.

- 613, ligne 6: au lieu de erecto, lisez recto.

- 613, ligne 7: au lieu de extipellata, lisez estipellata.

- 619, ligne 4: au lieu de dans l'ovaire, lisez dans l'akène.

_ 619, ligne 5 : au lieu de ovaire adulte, lisez ovaire; adulte.

Le Secrétariat, tout en apportant le plus grand soin à la correction des épreuves, ne saurait être rendu responsable des fautes échappées aux auteurs, et.il ne se charge pas d'en faire le relevé; mais celles qui lui sont signalées en temps utile peuvent être l'objet de notes rectificatives ou d'errata insérés à la fin du volume. 


\title{
AVIS AU RELIEUR.
}

Planches. - Ce volume renferme 19 planches qu'on peut réunir à la fin du volume ou placer de la manière suivante :

Planches I, II, III et IV (Mentha Schultzii, etc.).. en regard de la page 132

- V (Acer lanceolatum Molliard sp. nov.)..

- VI(Festuca, schémas des coupes de feuilles d'innovations) ..................

- VIl (Centaurea diffuso $\times$ maculosa $). .$.

- VIII (Portrait d'Émile Bescherelle)......

- IX (Tige anormale de Vipérine)........

- $\quad \mathbf{X}$ (Carte de la flore bretonne)..........

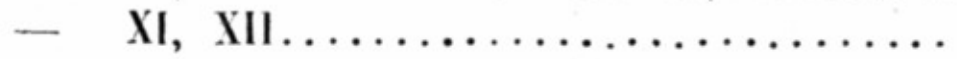

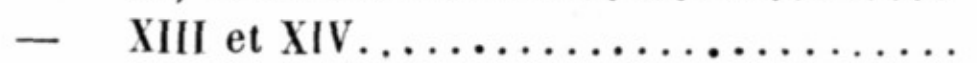

- XV (Nucularia Perrini nov. gen.)......

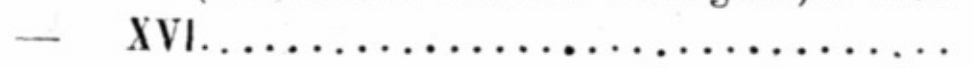

- XVII (Clemalis otophora, etc.)........ 325

- XVIII (Lepidagathis Pobeguini Hua sp. nov. $). . \ldots \ldots \ldots \ldots \ldots \ldots \ldots \ldots \ldots \ldots$

- XIX (Thalictrum osmundifolium, etc.). 381 382

Classement du texte. - Comptes rendus des séances, Revue bibliographique et Tables, 720 pages.

Le Secrétaire général de la Société, gérant du Bullotin (1904),

\author{
E. MaLINVAUd.
}



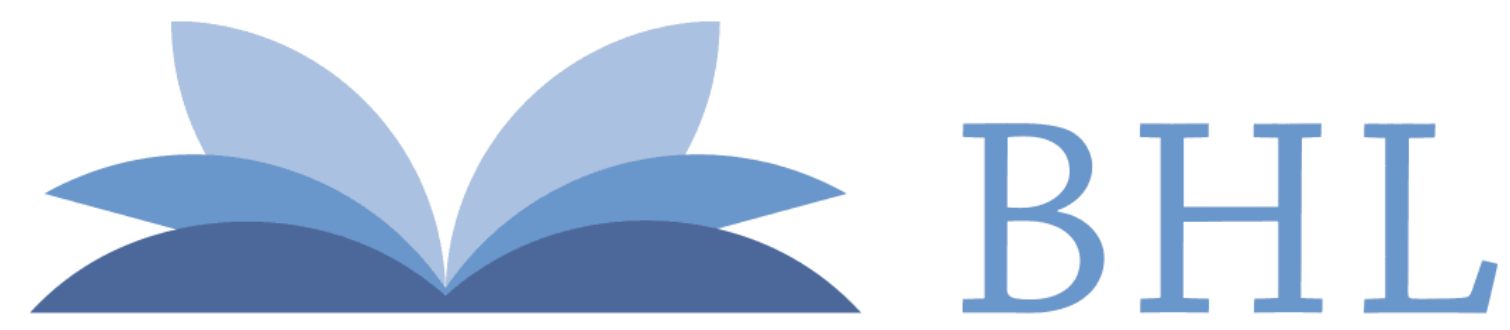

\section{Biodiversity Heritage Library}

1903. "Addenda et Errata." Bulletin de la Société botanique de France 50, 718-720. https://doi.org/10.1080/00378941.1903.10831079.

View This Item Online: https://www.biodiversitylibrary.org/item/8672

DOI: https://doi.org/10.1080/00378941.1903.10831079

Permalink: https://www.biodiversitylibrary.org/partpdf/160311

\section{Holding Institution}

Missouri Botanical Garden, Peter H. Raven Library

\section{Sponsored by}

Missouri Botanical Garden

\section{Copyright \& Reuse}

Copyright Status: Public domain. The BHL considers that this work is no longer under copyright protection.

This document was created from content at the Biodiversity Heritage Library, the world's largest open access digital library for biodiversity literature and archives. Visit BHL at https://www.biodiversitylibrary.org. 